\title{
Two-Step Viscosity Approximation Scheme for Variational Inequality in Banach Spaces
}

\author{
Liping Yang and Weiming Kong \\ School of Applied Mathematics, Guangdong University of Technology, Guangzhou 510520, China \\ Correspondence should be addressed to Liping Yang; yanglp99@126.com
}

Received 29 December 2013; Accepted 13 February 2014; Published 24 March 2014

Academic Editor: Adrian Petrusel

Copyright ( 2014 L. Yang and W. Kong. This is an open access article distributed under the Creative Commons Attribution License, which permits unrestricted use, distribution, and reproduction in any medium, provided the original work is properly cited.

\begin{abstract}
This paper introduces and analyzes a viscosity iterative algorithm for an infinite family of nonexpansive mappings $\left\{T_{i}\right\}_{i=1}^{\infty}$ in the framework of a strictly convex and uniformly smooth Banach space. It is shown that the proposed iterative method converges strongly to a common fixed point of $\left\{T_{i}\right\}_{i=1}^{\infty}$, which solves specific variational inequalities. Necessary and sufficient convergence conditions of the iterative algorithm for an infinite family of nonexpansive mappings are given. Results shown in this paper represent an extension and refinement of the previously known results in this area.
\end{abstract}

\section{Introduction}

The variational inequality problem was first introduced by Hartman and Stampacchia [1]. This problem has achieved increasing attention in many research fields, such as mathematical programming, constrained linear and nonlinear optimization, automatic control, manufacturing system design, signal and image processing, and complementarity problem in economics and pattern recognition (see [2-4] and the references therein). Nowadays, the theory of variational inequalities and fixed point theory are two important and dynamic areas in nonlinear analysis and optimization.

One promising approach to handle these problems is to develop iterative schemes to compute the approximate solutions of variational inequalities and to find a common fixed point of a given family of operators. There is a variety of techniques to suggest and analyze various iterative algorithms for solving variational inequalities and the related optimization problems. The fixed point theory has played an important role in the development of various algorithms for solving variational inequalities.

In this paper, the purpose is to develop a new iterative method for solving a specific variational inequality.

Let $E$ be a real Banach space and $K$ a nonempty closed convex subset of $E$. Recall that a mapping $f: K \rightarrow K$ is said to be a contraction on $K$ if there is a constant $\alpha \in(0,1)$ such that $\|f(x)-f(y)\| \leq \alpha\|x-y\|$ for all $x, y \in K$. We use $\Pi_{K}$ to denote the collection of all contractions on $K$. That is, $\Pi_{K}=$ $\{f \mid f: K \rightarrow K$ is acontraction with constant $\alpha\}$. A mapping $T: K \rightarrow K$ is said to be nonexpansive if $\|T x-T y\| \leq\|x-y\|$ for all $x, y \in K$. We denote by $F(T)$ the set of fixed points of mapping $T$; that is, $F(T)=\{x \in K: T x=x\}$.

Iterative methods for nonexpansive mappings have recently been applied to solve convex minimization problems (see [5-8] and the references therein). A typical problem is to minimize a quadratic function over the set of the fixed points of a nonexpansive mapping on a real Hilbert space $H$ :

$$
\min _{x \in F(T)}\langle B x, x\rangle-h(x)
$$

where $B$ is a linear bounded operator defined on $H, F(T)$ is the fixed point set of the nonexpansive mapping $T$, and $h$ is a potential function for $\gamma f$ (i.e., $h^{\prime}(x)=\gamma f(x)$ for all $x \in H$ ).

Let $T: K \rightarrow K$ be a nonexpansive mapping. For given $f \in \Pi_{K}$ and $t \in(0,1)$ define a contraction mapping $T_{t}^{f}$ : $K \rightarrow K$ by

$$
T_{t}^{f} x=t f(x)+(1-t) T x, \quad x \in K .
$$

It follows from Banach's contraction principle that it yields a unique fixed point $z_{t} \in K$ of $T_{t}^{f}$; that is, $z_{t}$ is the unique solution of the following equation:

$$
z_{t}=t f\left(z_{t}\right)+(1-t) T z_{t} .
$$


Moudafi [9] first proposed the viscosity approximation method and proved that if $E$ is a real Hilbert space, then the sequence $\left\{z_{t}\right\}$ converges strongly to a fixed point $x^{*}$ of $T$ in $K$ which is the unique solution to the following variational inequality:

$$
\left\langle(I-f) x^{*}, x-x^{*}\right\rangle \geq 0, \quad x \in F(T) .
$$

In 2004, Xu [10] extended Moudafi's results [9] to the framework of uniformly smooth Banach spaces and proved the strong convergence of both the continuous scheme and iterative scheme. Very recently, Yao et al. [11] introduced the following iteration scheme:

$$
\begin{aligned}
x_{0} & =x \in K \text { chosen arbitrarily, } \\
y_{n} & =\beta_{n} x_{n}+\left(1-\beta_{n}\right) T x_{n}, \\
x_{n+1} & =\alpha_{n} f\left(x_{n}\right)+\left(1-\alpha_{n}\right) y_{n}, \quad f \in \Pi_{K}, n \geq 0,
\end{aligned}
$$

where the sequences $\left\{\alpha_{n}\right\}$ and $\left\{\beta_{n}\right\} \subset[0,1]$. By using the viscosity approximation method, they proved that the approximate solutions converge strongly to a solution of a variational inequality under some mild conditions.

Let $\left\{T_{n}\right\}_{n=1}^{\infty}: K \rightarrow K$ be an infinite family of nonexpansive mappings and let $\gamma_{1}, \gamma_{2}, \ldots$ be real numbers such that $0 \leq \gamma_{n} \leq 1$ for every $i \in \mathbb{N}$ (the set of positive integers). Let $I$ be the identity operator on a real Banach space $E$. For any $n \in \mathbb{N}$, the mapping $W_{n}$ is defined by

$$
\begin{aligned}
U_{n, n+1} & =I, \\
U_{n, n} & =\gamma_{n} T_{n} U_{n, n+1}+\left(1-\gamma_{n}\right) I, \\
U_{n, n-1} & =\gamma_{n-1} T_{n-1} U_{n, n}+\left(1-\gamma_{n-1}\right) I, \\
& \vdots \\
U_{n, k} & =\gamma_{k} T_{k} U_{n, k+1}+\left(1-\gamma_{k}\right) I, \\
U_{n, k-1} & =\gamma_{k-1} T_{k-1} U_{n, k}+\left(1-\gamma_{k-1}\right) I, \\
& \vdots \\
U_{n, 2} & =\gamma_{2} T_{2} U_{n, 3}+\left(1-\gamma_{2}\right) I, \\
W_{n} & =U_{n, 1}=\gamma_{1} T_{1} U_{n, 2}+\left(1-\gamma_{1}\right) I .
\end{aligned}
$$

Such a mapping $W_{n}$ is called the $W$-mapping generated by $T_{n}, T_{n-1}, \ldots, T_{1}$ and $\gamma_{n}, \gamma_{n-1}, \ldots, \gamma_{1}$ (see [12]). Nonexpansivity of each $T_{i}$ ensures the nonexpansivity of $W_{n}$.

Shimoji and Takahashi [12] first introduced an iterative algorithm given by an infinite family of nonexpansive mappings. Furthermore, they considered the feasibility problem of finding a solution of infinite convex inequalities and the problem of finding a common fixed point of infinite nonexpansive mappings. Bauschke and Borwein [13] pointed out that the well-known convex feasibility problem reduces to finding a point in the intersection of the fixed point sets of a family of nonexpansive mappings. The problem of finding an optimal point that minimizes a given cost function over the common set of fixed points of a family of nonexpansive mappings is of wide interdisciplinary interest and practical importance (see [14]). A simple algorithmic solution to the problem of minimizing a quadratic function over the common set of fixed points of a family of nonexpansive mappings is of extreme value in many applications including set theoretic signal estimation (see $[14,15]$ ). It is now one of the main tools in studying convergence of iterative methods for approaching a common fixed point of an infinite family of nonlinear mappings.

Cho et al. [16] proposed the following iterative scheme:

$$
\begin{aligned}
x_{0} & =x \in K \text { chosen arbitrarily, } \\
y_{n} & =\beta_{n} x_{n}+\left(1-\beta_{n}\right) W_{n} x_{n}, \\
x_{n+1} & =\alpha_{n} f\left(x_{n}\right)+\left(1-\alpha_{n}\right) y_{n}, \quad f \in \Pi_{K}, n \geq 0,
\end{aligned}
$$

where $\left\{W_{n}\right\}$ is defined by (6) and the sequences $\left\{\alpha_{n}\right\}$ and $\left\{\beta_{n}\right\}$ are in $[0,1]$. Under some conditions, they proved the strong convergence of the sequence $\left\{x_{n}\right\}$ defined by (7) and extended the results of [11].

Motivated and inspired by the earlier methods proposed in the literature and their convergence, we consider the following two-step viscosity approximation method for finding common fixed point of an infinite family of nonexpansive mappings $\left\{T_{i}\right\}_{i=1}^{\infty}$ :

$$
\begin{aligned}
x_{0} & =x \in K, \\
y_{n} & =b_{n} x_{n}+\left(1-b_{n}\right) W_{n} x_{n}, \\
x_{n+1} & =\alpha_{n} f\left(y_{n}\right)+\beta_{n} x_{n}+\left(1-\alpha_{n}-\beta_{n}\right) W_{n} y_{n}, \quad \forall n \geq 0,
\end{aligned}
$$

where $\left\{\alpha_{n}\right\},\left\{b_{n}\right\},\left\{\beta_{n}\right\}$, and $\left\{\alpha_{n}+\beta_{n}\right\} \subset(0,1)$ and $f \in \Pi_{K}$. By using viscosity approximation methods, the purpose of this paper is to study necessary and sufficient conditions for the convergence of the iterative algorithm (8) for finding approximate common fixed points of an infinite countable family of nonexpansive mappings $\left\{T_{i}\right\}_{i=1}^{\infty}$. The results presented in this paper extend and improve some recent results.

\section{Preliminaries}

Let $E$ be a Banach space with dimension $E \geq 2$ and let $E^{*}$ be its dual. The modulus of convexity of $E$ is the function $\delta_{E}$ : $(0,2] \rightarrow[0,1]$ defined by

$$
\delta_{E}(\varepsilon)=\inf \left\{1-\frac{1}{2}\|x+y\|:\|x\|=\|y\|=1,\|x-y\|=\varepsilon\right\} .
$$

A Banach space $E$ is uniformly convex if and only if $\delta_{E}(\varepsilon)>0$ for all $\varepsilon \in(0,2]$. A Banach space $E$ is said to be strictly convex if

$$
\|x\|=\|y\|=1 \quad \text { for } x \neq y \text { implies } \frac{\|x+y\|}{2}<1 .
$$

Suppose that $\left\{x_{n}\right\}$ is a sequence in $E$; then $x_{n} \rightarrow x$ (resp., $x_{n} \rightarrow x$ ) will denote strong (resp., weak) convergence of the sequence $\left\{x_{n}\right\}$ to $x$. 
Let the value of $f \in E^{*}$ at $x \in E$ be denoted by $\langle x, f\rangle$. The normalized duality mapping $J$ from $E$ into $2^{E^{*}}$ is defined by

$$
J(x)=\left\{f \in E^{*}:\langle x, f\rangle=\|x\|^{2}=\|f\|^{2}\right\}, \quad \forall x \in E,
$$

where $E^{*}$ denotes the dual space of a real Banach space $E$.

Let $S(E)=\{x \in E:\|x\|=1\}$. The norm $\|\cdot\|$ of $E$ is said to be Gâteaux differentiable (and $E$ is said to be smooth) if the limit

$$
\lim _{t \rightarrow 0} \frac{\|x+t y\|-\|x\|}{t}
$$

exists for all $x, y \in S(E)$. The norm is said to be uniformly Gâteaux differentiable if, for all $y \in S(E)$, the limit is attained uniformly for each $x \in S(E)$. The norm $\|\cdot\|$ of $E$ is said to be Fréchet differentiable if, for all $x \in S(E)$, the limit exists uniformly for each $y \in S(E)$. The norm $\|\cdot\|$ of $E$ is said to be uniformly Fréchet differentiable (or $E$ is said to be uniformly smooth) if the limit is attained uniform for all $x, y \in S(E)$. It is well known that (uniform) Fréchet differentiability of the norm $E$ implies (uniform) Gâteaux differentiability of norm $E$. It is known (see [17]) that if $E$ is smooth, then the normalized duality mapping $J$ is single-valued and norm to weak star continuous. And we know that if the norm of $E$ is uniformly Gâteaux differentiable, then the normalized duality mapping is norm to weak star uniformly continuous on each bounded subset of $E$.

Let $C$ and $D$ be nonempty subsets of a Banach space $E$ such that $C$ is nonempty closed convex and $D \subset C$; then a mapping $P: C \rightarrow D$ is said to be a retraction if $P x=x$ for all $x \in C$. A retraction $P: C \rightarrow D$ is said to be sunny [18] if $P(P x+t(x-P x))=P x$ for all $x \in C$ and $t \geq 0$ with $P x+t(x-P x) \in C$. A sunny nonexpansive retraction is a sunny retraction, which is also a nonexpansive mapping. In a smooth Banach space $E$, it is well known [18] that $P$ is a sunny nonexpansive retraction from $C$ to $D$ if and only if the following inequality holds:

$$
\langle x-P x, J(z-P x)\rangle \leq 0, \quad \forall x \in C, z \in D .
$$

Concerning $W_{n}$, the next lemmas play a crucial role for proving our main results.

Lemma 1 (cf. [12]). Let $K$ be a nonempty, closed, and convex subset of a strictly convex Banach space E. Let $T_{1}, T_{2}, \ldots$ be nonexpansive mappings of $K$ into itself such that $\bigcap_{n=1}^{\infty} F\left(T_{n}\right)$ is nonempty and let $\gamma_{1}, \gamma_{2}, \ldots$ be real numbers such that $0<$ $\gamma_{n} \leq b<1$ for any $n \geq 1$. Then, for any $x \in K$ and $k \in \mathbb{N}$, the limit $\lim _{n \rightarrow \infty} U_{n, k} x$ exists.

Using Lemma 1, we can define the mapping $W$ of $K$ into itself as follows:

$$
W x=\lim _{n \rightarrow \infty} W_{n} x=\lim _{n \rightarrow \infty} U_{n, 1} x, \quad \forall x \in K .
$$

Such a mapping $W$ is said to be the $W$-mapping generated by $T_{1}, T_{2}, \ldots$ and $\gamma_{1}, \gamma_{2}, \ldots$ Throughout this paper, we will assume that $0<\gamma_{n} \leq b<1$ for all $n \geq \mathbb{N}$.
Lemma 2 (cf. [12]). Let $K$ be a nonempty, closed, and convex subset of a strictly convex Banach space E. Let $T_{1}, T_{2}, \ldots$ be nonexpansive mappings of $K$ into itself such that $\bigcap_{n=1}^{\infty} F\left(T_{n}\right)$ is nonempty and let $\gamma_{1}, \gamma_{2}, \ldots$ be real numbers such that $0<$ $\gamma_{n} \leq b<1$ for any $n \geq 1$. Then $F(W)=\bigcap_{n=1}^{\infty} F\left(T_{n}\right)$.

We also need the following lemmas for the proof of our main results.

Lemma 3. Let $E$ be a real Banach space and let $J: E \rightarrow 2^{E^{*}}$ be the normalized duality mapping; then for any $x, y \in E$ the following inequality holds:

$$
\|x+y\|^{2} \leq\|x\|^{2}+2\langle y, j(x+y)\rangle, \quad j(x+y) \in J(x+y) .
$$

Lemma 4 (cf. [19], Lemma 2.5). Let $\left\{a_{n}\right\}$ be a sequence of nonnegative real numbers satisfying the following relation:

$$
a_{n+1} \leq\left(1-\lambda_{n}\right) a_{n}+\lambda_{n} \sigma_{n}+\mu_{n}, \quad n \geq 0,
$$

where (i) $\left\{\lambda_{n}\right\} \subset[0,1], \sum_{n=1}^{\infty} \lambda_{n}=\infty$; (ii) lim $\sup _{n \rightarrow \infty} \sigma_{n} \leq 0$; (iii) $\mu_{n} \geq 0, \sum_{n=1}^{\infty} \mu_{n}<\infty$. Then $\left\{a_{n}\right\}$ converges to zero as $n \rightarrow$ $\infty$.

Lemma 5 (cf. [20]). Let $\left\{x_{n}\right\},\left\{y_{n}\right\}$ be two bounded sequences in a Banach space $E$ and $\beta_{n} \in[0,1]$ with $0<\liminf _{n \rightarrow \infty} \beta_{n} \leq$ $\limsup _{n \rightarrow \infty} \beta_{n}<1$. Suppose that $x_{n+1}=\beta_{n} y_{n}+\left(1-\beta_{n}\right) x_{n}$ for all integers $n \geq 0$ and $\lim \sup _{n \rightarrow \infty}\left(\left\|y_{n+1}-y_{n}\right\|-\left\|x_{n+1}-x_{n}\right\|\right) \leq$ 0 . Then $\lim _{n \rightarrow \infty}\left\|x_{n}-y_{n}\right\|=0$.

It follows from [10, Theorem 4.1] that we have the following results.

Lemma 6 (cf. [10]). Let $E$ be a uniformly smooth Banach space. Let $K$ be a nonempty, closed, and convex subset of $E$, and let $T: K \rightarrow K$ be a nonexpansive mapping with $F(T) \neq \emptyset$ and $f \in \Pi_{K}$. Then the sequence $\left\{x_{t}\right\}$ defined by

$$
x_{t}=t f\left(x_{t}\right)+(1-t) T x_{t}
$$

converges strongly to a fixed point of $\mathrm{T}$ as $t \rightarrow 0$. If we define $P: \Pi_{K} \rightarrow F(T)$ by

$$
P(f):=\lim _{t \rightarrow 0} x_{t}, \quad \forall f \in \Pi_{K},
$$

then $P(f)$ solves the following variational inequality:

$$
\begin{array}{r}
\langle(I-f) P(f), J(P(f)-p)\rangle \leq 0, \\
\forall f \in \Pi_{K}, \quad p \in F(T) .
\end{array}
$$

In particular, if $f=u \in K$ is a constant, then (19) is reduced to the sunny nonexpansive retraction from $K$ onto $F(T)$ :

$$
\langle P(u)-u, J(P(u)-p)\rangle \leq 0, \quad u \in K, p \in F(T) .
$$

\section{Main Results}

In the sequel, $F=\bigcap_{i=1}^{\infty} F\left(T_{i}\right)$ denotes the set of common fixed points for a family of nonexpansive mappings $\left\{T_{i}\right\}_{i=1}^{\infty}$. 
Lemma 7. Let E be a real strictly convex and uniformly smooth Banach space. Let $K$ be a nonempty, closed, and convex subset of $E$ and let $T_{i}$ be a nonexpansive mapping from $K$ into itselffor $i \in \mathbb{N}$. Assume that $F=\bigcap_{i=1}^{\infty} F\left(T_{i}\right) \neq \emptyset$ and $f \in \Pi_{K}$. Suppose that the sequences $\left\{\alpha_{n}\right\},\left\{\beta_{n}\right\},\left\{b_{n}\right\}$, and $\left\{\alpha_{n}+\beta_{n}\right\}$ in $(0,1)$ satisfy the following conditions:

(1) $\lim _{n \rightarrow \infty} \alpha_{n}=0, \sum_{n=1}^{\infty} \alpha_{n}=\infty$ and $0<$ $\liminf _{n \rightarrow \infty} \beta_{n} \leq \lim \sup _{n \rightarrow \infty} \beta_{n}<1$;

(2) $\lim _{n \rightarrow \infty}\left|b_{n+1}-b_{n}\right|=0$ and $\liminf _{n \rightarrow \infty} b_{n}>0$.

Let the two-step viscosity approximation iterative scheme $\left\{x_{n}\right\}$ be defined by (8). Then

(i) the sequence $\left\{x_{n}\right\}$ is bounded;

(ii) $\lim _{n \rightarrow \infty}\left\|x_{n+1}-x_{n}\right\|=0$;

(iii) $\lim _{n \rightarrow \infty}\left\|W x_{n}-x_{n}\right\|=0$.

Proof. (i) We should prove that $\left\|x_{n}-p\right\| \leq \max \left\{\| x_{0}-\right.$ $p\|,(1 /(1-\alpha))\| f(p)-p \|\}$ for all $n \geq 0$ and given $p \in F$ and so $\left\{y_{n}\right\},\left\{z_{n}\right\},\left\{f\left(x_{n}\right)\right\},\left\{W_{n} x_{n}\right\},\left\{W_{n} y_{n}\right\}$, and $\left\{W_{n} z_{n}\right\}$ are bounded.

Indeed, take a given $p \in F$. It follows from (8) that

$$
\begin{aligned}
\left\|y_{n}-p\right\| & =\left\|b_{n}\left(x_{n}-p\right)+\left(1-b_{n}\right)\left(W_{n} x_{n}-p\right)\right\| \\
& \leq b_{n}\left\|x_{n}-p\right\|+\left(1-b_{n}\right)\left\|W_{n} x_{n}-p\right\| \leq\left\|x_{n}-p\right\| .
\end{aligned}
$$

It follows from (8) and (21) that

$$
\begin{aligned}
\left\|x_{n+1}-p\right\|= & \| \alpha_{n}\left(f\left(y_{n}\right)-p\right)+\beta_{n}\left(x_{n}-p\right) \\
& +\left(1-\alpha_{n}-\beta_{n}\right)\left(W_{n} y_{n}-p\right) \| \\
\leq & \alpha_{n}\left(\left\|f\left(y_{n}\right)-f(p)\right\|+\|f(p)-p\|\right) \\
& +\beta_{n}\left\|x_{n}-p\right\|+\left(1-\alpha_{n}-\beta_{n}\right)\left\|y_{n}-p\right\| \\
\leq & \left(1-\alpha_{n}\right)\left\|x_{n}-p\right\|+\alpha_{n} \alpha\left\|y_{n}-p\right\| \\
& +\alpha_{n}\|f(p)-p\| \leq\left(1-(1-\alpha) \alpha_{n}\right) \\
& \times\left\|x_{n}-p\right\|+\alpha_{n}\|f(p)-p\| \\
\leq & \max \left\{\left\|x_{n}-p\right\|, \frac{1}{1-\alpha}\|f(p)-p\|\right\} .
\end{aligned}
$$

By mathematical induction, we obtain that

$$
\left\|x_{n}-p\right\| \leq \max \left\{\left\|x_{0}-p\right\|, \frac{1}{1-\alpha}\|f(p)-p\|\right\}
$$

for all $n \geq 0$. Hence, $\left\{x_{n}\right\}$ is bounded and so are $\left\{y_{n}\right\},\left\{z_{n}\right\}$, $\left\{f\left(x_{n}\right)\right\},\left\{W_{n} x_{n}\right\},\left\{W_{n} y_{n}\right\}$, and $\left\{W_{n} z_{n}\right\}$.

(ii) Putting $l_{n}=\left(x_{n+1}-\beta_{n} x_{n}\right) /\left(1-\beta_{n}\right)$, we have

$$
x_{n+1}=\beta_{n} x_{n}+\left(1-\beta_{n}\right) l_{n}, \quad \forall n \geq 0 .
$$

Then we have

$$
\begin{aligned}
l_{n+1}-l_{n}= & \frac{x_{n+2}-\beta_{n+1} x_{n+1}}{1-\beta_{n+1}}-\frac{x_{n+1}-\beta_{n} x_{n}}{1-\beta_{n}} \\
= & \left(\alpha_{n+1}\left(f\left(y_{n+1}\right)-W_{n+1} y_{n+1}\right)\right. \\
& \left.+\left(1-\beta_{n+1}\right) W_{n+1} y_{n+1}\right) \times\left(1-\beta_{n+1}\right)^{-1} \\
& -\frac{\alpha_{n}\left(f\left(y_{n}\right)-W_{n} y_{n}\right)+\left(1-\beta_{n}\right) W_{n} y_{n}}{1-\beta_{n}} \\
= & \frac{\alpha_{n+1}}{1-\beta_{n+1}}\left(f\left(y_{n+1}\right)-W_{n+1} y_{n+1}\right) \\
& -\frac{\alpha_{n}}{1-\beta_{n}}\left(f\left(y_{n}\right)-W_{n} y_{n}\right) \\
& +\left(W_{n+1} y_{n+1}-W_{n+1} y_{n}\right)+\left(W_{n+1} y_{n}-W_{n} y_{n}\right), \\
\left\|y_{n+1} y_{n}\right\|= & \| b_{n+1} x_{n+1}+\left(1-b_{n+1}\right) W_{n+1} x_{n+1} \\
& -b_{n} x_{n}-\left(1-b_{n}\right) W_{n} x_{n} \| \\
\leq & b_{n+1}\left\|x_{n+1}-x_{n}\right\|+\left(1-b_{n+1}\right) \\
& \times\left\|W_{n+1} x_{n+1}-W_{n+1} x_{n}\right\| \\
& +\left|b_{n+1}-b_{n}\right|\left(\left\|x_{n}\right\|+\left\|W_{n} x_{n}\right\|\right)+\left(1-b_{n+1}\right) \\
& \times\left\|W_{n+1} x_{n}-W_{n} x_{n}\right\| \\
& +x_{n+1}-x_{n} \|+\left|b_{n+1}-b_{n}\right|\left(\left\|x_{n}\right\|+\left\|W_{n} x_{n}\right\|\right) \\
& x_{n}-W_{n} x_{n} \| . \\
& \\
& \\
&
\end{aligned}
$$

Since $T_{i}$ and $U_{n, i}$ are nonexpansive, from (6), we obtain

$$
\begin{aligned}
\left\|W_{n+1} x_{n}-W_{n} x_{n}\right\| & =\gamma_{1}\left\|T_{1} U_{n+1,2} x_{n}-T_{1} U_{n, 2} x_{n}\right\| \\
& \leq \gamma_{1}\left\|U_{n+1,2} x_{n}-U_{n, 2} x_{n}\right\| \\
& =\gamma_{1}\left\|\gamma_{2} T_{2} U_{n+1,3} x_{n}-\gamma_{2} T_{2} U_{n, 3} x_{n}\right\| \\
& \leq \gamma_{1} \gamma_{2}\left\|U_{n+1,3} x_{n}-U_{n, 3} x_{n}\right\| \\
& =\gamma_{1} \gamma_{2}\left\|\gamma_{3} T_{3} U_{n+1,4} x_{n}-\gamma_{3} T_{3} U_{n, 4} x_{n}\right\| \\
& \leq \gamma_{1} \gamma_{2} \gamma_{3}\left\|U_{n+1,4} x_{n}-U_{n, 4} x_{n}\right\| \\
& \leq \cdots \\
& \leq \gamma_{1} \gamma_{2} \gamma_{3} \cdots \gamma_{n}\left\|U_{n+1, n+1} x_{n}-U_{n, n+1} x_{n}\right\| \\
& \leq M \prod_{i=1}^{n} \gamma_{i},
\end{aligned}
$$

where $M \geq 0$ is a constant such that $\left\|U_{n+1, n+1} x_{n}-U_{n, n+1} x_{n}\right\| \leq$ $M$ for all $n \geq 0$. Similarly, we have

$$
\left\|W_{n+1} y_{n}-W_{n} y_{n}\right\| \leq M_{1} \prod_{i=1}^{n} \gamma_{i},
$$


where $M_{1} \geq 0$ is a constant such that $\left\|U_{n+1, n+1} y_{n}-U_{n, n+1} y_{n}\right\| \leq$ $M_{1}$ for all $n \geq 0$. Combining (25), (26), and (27), we have

$$
\begin{aligned}
\| l_{n+1} & -l_{n}\|-\| x_{n+1}-x_{n} \| \\
\leq & \frac{\alpha_{n+1}}{1-\beta_{n+1}}\left(\left\|f\left(y_{n+1}\right)\right\|+\left\|W_{n+1} y_{n+1}\right\|\right) \\
& +\frac{\alpha_{n}}{1-\beta_{n}}\left(\left\|f\left(y_{n}\right)\right\|+\left\|W_{n} y_{n}\right\|\right) \\
& +\left\|y_{n+1}-y_{n}\right\|+\left\|W_{n+1} y_{n}-W_{n} y_{n}\right\| \\
& -\left\|x_{n+1}-x_{n}\right\| \leq \frac{\alpha_{n+1}}{1-\beta_{n+1}} \\
& \times\left(\left\|f\left(y_{n+1}\right)\right\|+\left\|W_{n+1} y_{n+1}\right\|\right) \\
& +\frac{\alpha_{n}}{1-\beta_{n}}\left(\left\|f\left(y_{n}\right)\right\|+\left\|W_{n} y_{n}\right\|\right) \\
& +\left|b_{n+1}-b_{n}\right|\left(\left\|x_{n}\right\|+\left\|W_{n} x_{n}\right\|\right) \\
& +\left(M+M_{1}\right) \prod_{i=1}^{n} \gamma_{i} .
\end{aligned}
$$

From conditions (1), (2), and $0<\gamma_{n} \leq b<1$, we get

$$
\limsup _{n \rightarrow \infty}\left(\left\|l_{n+1}-l_{n}\right\|-\left\|x_{n+1}-x_{n}\right\|\right) \leq 0 \text {. }
$$

It follows from Lemma 5 that $\lim _{n \rightarrow \infty}\left\|l_{n}-x_{n}\right\|=0$. Noting (24), we obtain

$$
x_{n+1}-x_{n}=\left(1-\beta_{n}\right)\left(l_{n}-x_{n}\right) .
$$

Thus, we get that $\lim _{n \rightarrow \infty}\left\|x_{n+1}-x_{n}\right\|=0$ holds.

(iii) Observe that

$$
\begin{aligned}
\| x_{n}- & W_{n} x_{n}\|-\| x_{n+1}-x_{n} \| \\
\leq & \left\|x_{n+1}-W_{n} x_{n}\right\| \\
= & \| \alpha_{n}\left(f\left(y_{n}\right)-W_{n} x_{n}\right)+\beta_{n}\left(x_{n}-W_{n} x_{n}\right) \\
& +\left(1-\alpha_{n}-\beta_{n}\right)\left(W_{n} y_{n}-W_{n} x_{n}\right) \| \\
\leq & \alpha_{n}\left\|f\left(y_{n}\right)-W_{n} x_{n}\right\|+\beta_{n}\left\|x_{n}-W_{n} x_{n}\right\| \\
& +\left(1-\alpha_{n}-\beta_{n}\right)\left\|W_{n} y_{n}-W_{n} x_{n}\right\| \\
\leq & \alpha_{n}\left\|f\left(y_{n}\right)-W_{n} x_{n}\right\|+\beta_{n}\left\|x_{n}-W_{n} x_{n}\right\| \\
& +\left(1-\alpha_{n}-\beta_{n}\right)\left\|y_{n}-x_{n}\right\| \\
= & \alpha_{n}\left\|f\left(y_{n}\right)-W_{n} x_{n}\right\|+\beta_{n}\left\|x_{n}-W_{n} x_{n}\right\| \\
& +\left(1-\alpha_{n}-\beta_{n}\right)\left(1-b_{n}\right)\left\|x_{n}-W_{n} x_{n}\right\| \\
= & \alpha_{n}\left\|f\left(y_{n}\right)-W_{n} x_{n}\right\|+\left(1-\alpha_{n}\left(1-b_{n}\right)\right) \\
& \times
\end{aligned}
$$

which implies that

$$
\begin{aligned}
& \left(1-\beta_{n}\right) b_{n}\left\|x_{n}-W_{n} x_{n}\right\| \leq\left\|x_{n+1}-x_{n}\right\| \\
& \quad+\alpha_{n}\left(\left\|f\left(y_{n}\right)-W_{n} x_{n}\right\|+\left\|x_{n}-W_{n} x_{n}\right\|\right) .
\end{aligned}
$$

Since $0<\liminf _{n \rightarrow \infty} \beta_{n} \leq \limsup _{n \rightarrow \infty} \beta_{n}<1$ and $\liminf _{n \rightarrow \infty} b_{n}>0$, there exists an integer $n_{0} \geq 1$ such that

$$
a \leq \beta_{n} \leq b, \quad b_{n} \geq a, \quad \forall n \geq n_{0}
$$

for some constants $a, b \in(0,1)$. Hence we conclude that, for all $n \geq n_{0}$,

$$
\begin{aligned}
a(1-b)\left\|x_{n}-W_{n} x_{n}\right\| & \leq\left(1-\beta_{n}\right) b_{n}\left\|x_{n}-W_{n} x_{n}\right\| \\
& \leq\left\|x_{n+1}-x_{n}\right\|+\alpha_{n}\left(\left\|f\left(y_{n}\right)-W_{n} x_{n}\right\|\right. \\
& \left.+\left\|x_{n}-W_{n} x_{n}\right\|\right) .
\end{aligned}
$$

Since $\lim _{n \rightarrow \infty} \alpha_{n}=0$ and $\lim _{n \rightarrow \infty}\left\|x_{n+1}-x_{n}\right\|=0$ and $\left\{x_{n}\right\}$, $\left\{y_{n}\right\}$, and $\left\{W_{n} x_{n}\right\}$ are bounded sequences, we have

$$
\lim _{n \rightarrow \infty}\left\|x_{n}-W_{n} x_{n}\right\|=0 .
$$

On the other hand, we have

$$
\left\|W x_{n}-x_{n}\right\| \leq\left\|W x_{n}-W_{n} x_{n}\right\|+\left\|W_{n} x_{n}-x_{n}\right\| .
$$

Since $\lim _{n \rightarrow \infty} W_{n} x=W x$ for any $x \in K$ and for any $\epsilon>0$, there exists a positive integer $N_{0}$ such that $\left\|W x-W_{n} x\right\| \leq \epsilon$ for all $x \in\left\{x_{n}\right\}$ and for all $n \geq N_{0}$. In particular, $\left\|W x_{n}-W_{n} x_{n}\right\| \leq \epsilon$ for all $n \geq N_{0}$. Thus we have that

$$
\left\|W x_{n}-W_{n} x_{n}\right\| \longrightarrow 0 \quad(n \longrightarrow \infty) .
$$

This together with (36) implies

$$
\lim _{n \rightarrow \infty}\left\|W x_{n}-x_{n}\right\|=0 \text {. }
$$

This completes the proof.

Theorem 8. Let $E$ be a real strictly convex and uniformly smooth Banach space. Let $K$ be a nonempty, closed, and convex subset of $E$ and let $T_{i}$ be a nonexpansive mapping from $K$ into itself for $i \in \mathbb{N}$. Assume that $F=\bigcap_{i=1}^{\infty} F\left(T_{i}\right) \neq \emptyset$ and $f \in \Pi_{K}$. Suppose that the sequences $\left\{\alpha_{n}\right\},\left\{\beta_{n}\right\},\left\{b_{n}\right\}$, and $\left\{\alpha_{n}+\beta_{n}\right\}$ in $(0,1)$ satisfy the following conditions:

(1) $\lim _{n \rightarrow \infty} \alpha_{n}=0, \sum_{n=1}^{\infty} \alpha_{n}=\infty$ and $0<$ $\liminf _{n \rightarrow \infty} \beta_{n} \leq \lim \sup _{n \rightarrow \infty} \beta_{n}<1 ;$

(2) $\lim _{n \rightarrow \infty}\left|b_{n+1}-b_{n}\right|=0$ and $\liminf _{n \rightarrow \infty} b_{n}>0$.

Then the two-step viscosity approximation iterative scheme $\left\{x_{n}\right\}$ defined by (8) converges strongly to $P(f) \in F$, where $P(f)$ is the unique solution of the following variational inequality:

$$
\langle(I-f) P(f), J(P(f)-p)\rangle \leq 0, \quad f \in \Pi_{K}, p \in F .
$$

Proof. It follows from Lemma 6 that there exists a solution $P(f)$ of a variational inequality:

$$
\langle(I-f) P(f), J(P(f)-p)\rangle \leq 0, \quad \forall f \in \Pi_{K}, p \in F .
$$

That is, $P(f)=\lim _{t \rightarrow 0} x_{t}$, where $x_{t}$ is defined by (17). 
We first show that $\lim _{\sup _{n \rightarrow \infty}}\langle P(f)-f(P(f)), J(P(f)-$ $\left.\left.x_{n}\right)\right\rangle \leq 0$, where $P(f)=\lim _{t \rightarrow 0^{+}} x_{t}$ with $x_{t}$ being the fixed point of the contraction:

$$
x \longmapsto t f(x)+(1-t) W x .
$$

Then, we can write

$$
x_{t}-x_{n_{j}}=t\left(f\left(x_{t}\right)-x_{n_{j}}\right)+(1-t)\left(W x_{t}-x_{n_{j}}\right) .
$$

Suppose that a subsequence $\left\{x_{n_{j}}\right\} \subset\left\{x_{n}\right\}$ is such that

$$
\begin{aligned}
& \limsup _{n \rightarrow \infty}\left\langle P(f)-f(P(f)), J\left(P(f)-x_{n}\right)\right\rangle \\
& \quad=\lim _{j \rightarrow \infty}\left\langle P(f)-f(P(f)), J\left(P(f)-x_{n_{j}}\right)\right\rangle
\end{aligned}
$$

and $x_{n_{j}} \rightarrow p$ for some $p \in E$. It follows from (38) that $\lim _{j \rightarrow \infty}\left\|x_{n_{j}}-W x_{n_{j}}\right\|=0$. Putting

$$
\begin{aligned}
f_{j}(t)= & (1-t)^{2}\left\|x_{n_{j}}-W x_{n_{j}}\right\| \\
& \times\left(2\left\|x_{t}-x_{n_{j}}\right\|+\left\|x_{n_{j}}-W x_{n_{j}}\right\|\right) \longrightarrow 0 \quad(j \longrightarrow \infty),
\end{aligned}
$$

it follows from (42), Lemma 3 , that

$$
\begin{aligned}
\left\|x_{t}-x_{n_{j}}\right\|^{2} \leq & (1-t)^{2}\left\|W x_{t}-x_{n_{j}}\right\|^{2} \\
& +2 t\left\langle f\left(x_{t}\right)-x_{n_{j}}, J\left(x_{t}-x_{n_{j}}\right)\right\rangle \\
\leq & (1-t)^{2}\left(\left\|W x_{t}-W x_{n_{j}}\right\|+\left\|W x_{n_{j}}-x_{n_{j}}\right\|\right)^{2} \\
& +2 t\left\langle f\left(x_{t}\right)-x_{t}, J\left(x_{t}-x_{n_{j}}\right)\right\rangle \\
& +2 t\left\langle x_{t}-x_{n_{j}}, J\left(x_{t}-x_{n_{j}}\right)\right\rangle \\
\leq & (1-t)^{2}\left\|x_{t}-x_{n_{j}}\right\|^{2}+f_{j}(t) \\
& +2 t\left\langle f\left(x_{t}\right)-x_{t}, J\left(x_{t}-x_{n_{j}}\right)\right\rangle \\
& +2 t\left\|x_{t}-x_{n_{j}}\right\|^{2} .
\end{aligned}
$$

The last inequality implies that

$$
\left\langle x_{t}-f\left(x_{t}\right), J\left(x_{t}-x_{n_{j}}\right)\right\rangle \leq \frac{t}{2}\left\|x_{t}-x_{n_{j}}\right\|^{2}+\frac{1}{2 t} f_{j}(t) .
$$

Letting $j \rightarrow \infty$ and noting (44) yield that

$$
\limsup _{j \rightarrow \infty}\left\langle x_{t}-f\left(x_{t}\right), J\left(x_{t}-x_{n_{j}}\right)\right\rangle \leq \frac{t}{2} M_{2},
$$

where $M_{1}>0$ is a constant such that $M_{2} \geq\left\|x_{t}-x_{n_{j}}\right\|^{2}$ for all $n \geq 0$ and $t \in(0,1)$. Taking $t \rightarrow 0$ in (47) and noticing the fact that the two limits are interchangeable due to the fact that $J$ is uniformly continuous on bounded subsets of $E$ from the strong topology of $E$ to the weak ${ }^{*}$ topology of $E^{*}$, we have

$$
\limsup _{j \rightarrow \infty}\left\langle P(f)-f(P(f)), J\left(P(f)-x_{n_{j}}\right)\right\rangle \leq 0 .
$$

Indeed, letting $t \rightarrow 0$, from (47) we have

$$
\limsup _{t \rightarrow 0} \limsup _{j \rightarrow \infty}\left\langle x_{t}-f\left(x_{t}\right), J\left(x_{t}-x_{n_{j}}\right)\right\rangle \leq 0 .
$$

Thus, for arbitrary $\epsilon>0$, there exists a positive number $\delta_{1}$ such that, for any $t \in\left(0, \delta_{1}\right)$, we have

$$
\limsup _{j \rightarrow \infty}\left\langle x_{t}-f\left(x_{t}\right), J\left(x_{t}-x_{n_{j}}\right)\right\rangle \leq \frac{\epsilon}{2} .
$$

Since $x_{t} \rightarrow P(f)$ as $t \rightarrow 0$, the set $\left\{x_{t}-x_{n_{j}}\right\}$ is bounded and the duality mapping $J$ is norm-to-norm uniformly continuous on bounded subset of $E$; there exists $\delta_{2}>0$ such that, for any $t \in\left(0, \delta_{2}\right)$,

$$
\begin{aligned}
& \mid\left\langle P(f)-f(P(f)), J\left(P(f)-x_{n_{j}}\right)\right\rangle \\
& -\left\langle x_{t}-f\left(x_{t}\right), J\left(x_{t}-x_{n_{j}}\right)\right\rangle \mid \\
& =\mid\left\langle P(f)-f(P(f)), J\left(P(f)-x_{n_{j}}\right)-J\left(x_{t}-x_{n_{j}}\right)\right\rangle \\
& \quad+\left\langle P(f)-f(P(f))-\left(x_{t}-f\left(x_{t}\right)\right), J\left(x_{t}-x_{n_{j}}\right)\right\rangle \mid \\
& \leq\left|\left\langle P(f)-f(P(f)), J\left(P(f)-x_{n_{j}}\right)-J\left(x_{t}-x_{n_{j}}\right)\right\rangle\right| \\
& \quad+\left\|P(f)-f(P(f))-\left(x_{t}-f\left(x_{t}\right)\right)\right\|\left\|x_{t}-x_{n_{j}}\right\|<\frac{\epsilon}{2} .
\end{aligned}
$$

Choose $\delta=\min \left\{\delta_{1}, \delta_{2}\right\}$; we have, for all $t \in(0, \delta)$ and $j \in \mathbb{N}$,

$$
\begin{gathered}
\left\langle P(f)-f(P(f)), J\left(P(f)-x_{n_{j}}\right)\right\rangle \\
\quad\left\langle\left\langle x_{t}-f\left(x_{t}\right), J\left(x_{t}-x_{n_{j}}\right)\right\rangle+\frac{\epsilon}{2},\right.
\end{gathered}
$$

which implies that

$$
\begin{gathered}
\limsup _{j \rightarrow \infty}\left\langle P(f)-f(P(f)), J\left(P(f)-x_{n_{j}}\right)\right\rangle \\
\quad \leq \limsup _{j \rightarrow \infty}\left\langle x_{t}-f\left(x_{t}\right), J\left(x_{t}-x_{n_{j}}\right)\right\rangle+\frac{\epsilon}{2} .
\end{gathered}
$$

This together with (50) implies that

$$
\limsup _{j \rightarrow \infty}\left\langle P(f)-f(P(f)), J\left(P(f)-x_{n_{j}}\right)\right\rangle \leq \epsilon .
$$

Since $\epsilon$ is arbitrary, we have that $\lim \sup _{j \rightarrow \infty}\langle P(f)-f(P(f))$, $\left.J\left(P(f)-x_{n_{j}}\right)\right\rangle \leq 0$. 
Next, we claim that $\lim _{n \rightarrow \infty}\left\|x_{n}-P(f)\right\|=0$. Indeed, notice that (35) implies that

$$
\begin{array}{r}
\left\|y_{n}-x_{n}\right\|=\left(1-b_{n}\right)\left\|W_{n} x_{n}-x_{n}\right\| \leq\left\|W_{n} x_{n}-x_{n}\right\| \\
\text { as } n \longrightarrow 0
\end{array}
$$

It follows from (8) and Lemma 3 that

$$
\begin{aligned}
& \left\|x_{n+1}-P(f)\right\|^{2} \\
& =\|\left(1-\alpha_{n}-\beta_{n}\right)\left(W_{n} y_{n}-P(f)\right) \\
& +\beta_{n}\left(x_{n}-P(f)\right)+\alpha_{n}\left(f\left(y_{n}\right)-P(f)\right) \|^{2} \\
& \leq\left\|\left(1-\alpha_{n}-\beta_{n}\right)\left(W_{n} y_{n}-P(f)\right)+\beta_{n}\left(x_{n}-P(f)\right)\right\|^{2} \\
& +2 \alpha_{n}\left\langle f\left(y_{n}\right)-P(f), J\left(x_{n+1}-P(f)\right)\right\rangle \\
& \leq\left(\left(1-\alpha_{n}-\beta_{n}\right)\left\|W_{n} y_{n}-P(f)\right\|+\beta_{n}\left\|x_{n}-P(f)\right\|\right)^{2} \\
& +2 \alpha_{n}\left\langle f\left(x_{n}\right)-f(P(f)), J\left(x_{n+1}-P(f)\right)\right\rangle \\
& +2 \alpha_{n}\left\langle f\left(y_{n}\right)-f\left(x_{n}\right), J\left(x_{n+1}-P(f)\right)\right\rangle \\
& +2 \alpha_{n}\left\langle f(P(f))-P(f), J\left(x_{n+1}-P(f)\right)\right\rangle \\
& \leq\left(1-\alpha_{n}\right)^{2}\left\|x_{n}-P(f)\right\|^{2}+2 \alpha \alpha_{n}\left\|x_{n}-P(f)\right\| \\
& \times\left\|x_{n+1}-P(f)\right\|+2 \alpha \alpha_{n}\left\|y_{n}-x_{n}\right\|\left\|x_{n+1}-P(f)\right\| \\
& +2 \alpha_{n}\left\langle f(P(f))-P(f), J\left(x_{n+1}-P(f)\right)\right\rangle \\
& \leq\left(1-\alpha_{n}\right)^{2}\left\|x_{n}-P(f)\right\|^{2}+\alpha \alpha_{n} \\
& \times\left(\left\|x_{n}-P(f)\right\|^{2}+\left\|x_{n+1}-P(f)\right\|^{2}\right) \\
& +2 \alpha \alpha_{n}\left\|y_{n}-x_{n}\right\|\left\|x_{n+1}-P(f)\right\| \\
& +2 \alpha_{n}\left\langle f(P(f))-P(f), J\left(x_{n+1}-P(f)\right)\right\rangle \\
& =\left(1-(2-\alpha) \alpha_{n}+\alpha_{n}^{2}\right)\left\|x_{n}-P(f)\right\|^{2} \\
& +\alpha \alpha_{n}\left\|x_{n+1}-P(f)\right\|^{2}+2 \alpha \alpha_{n}\left\|y_{n}-x_{n}\right\| \\
& \times\left\|x_{n+1}-P(f)\right\|+2 \alpha_{n}\langle f(P(f))-P(f) \text {, } \\
& \left.J\left(x_{n+1}-P(f)\right)\right\rangle .
\end{aligned}
$$

This implies that

$$
\begin{aligned}
& \left\|x_{n+1}-P(f)\right\|^{2} \\
& \leq \frac{1-(2-\alpha) \alpha_{n}}{1-\alpha \alpha_{n}} \\
& \quad \times\left\|x_{n}-P(f)\right\|^{2}+\frac{\alpha_{n}}{1-\alpha \alpha_{n}} \\
& \quad \times\left[\alpha_{n}\left\|x_{n}-P(f)\right\|^{2}+2 \alpha\left\|y_{n}-x_{n}\right\|\left\|x_{n+1}-P(f)\right\|\right. \\
& \left.\quad+2\left\langle f(P(f))-P(f), J\left(x_{n+1}-P(f)\right)\right\rangle\right]
\end{aligned}
$$

$$
\begin{aligned}
& =\left(1-\frac{2(1-\alpha) \alpha_{n}}{1-\alpha \alpha_{n}}\right)\left\|x_{n}-P(f)\right\|^{2}+\frac{\alpha_{n}}{1-\alpha \alpha_{n}} \\
& \times\left[\alpha_{n}\left\|x_{n}-P(f)\right\|^{2}+2 \alpha\left\|y_{n}-x_{n}\right\|\right. \\
& \quad \times\left\|x_{n+1}-P(f)\right\| \\
& \left.\quad+2\left\langle f(P(f))-P(f), J\left(x_{n+1}-P(f)\right)\right\rangle\right] \\
& \leq\left(1-\frac{2(1-\alpha) \alpha_{n}}{1-\alpha \alpha_{n}}\right)\left\|x_{n}-P(f)\right\|^{2}+\frac{\alpha_{n}}{1-\alpha \alpha_{n}} \\
& \times\left[\alpha_{n} M_{3}^{2}+2 \alpha\left\|y_{n}-x_{n}\right\| M_{3}\right. \\
& \left.\quad+2\left\langle f(P(f))-P(f), J\left(x_{n+1}-P(f)\right)\right\rangle\right],
\end{aligned}
$$

where $M_{3}=\sup _{n \geq 0}\left\|x_{n}-P(f)\right\|$. Set

$$
\begin{aligned}
\lambda_{n}= & \frac{2(1-\alpha) \alpha_{n}}{1-\alpha \alpha_{n}}, \\
\sigma_{n}= & \frac{\alpha_{n}}{2(1-\alpha)} M_{3}^{2}+\frac{\alpha}{1-\alpha}\left\|y_{n}-x_{n}\right\| M_{3} \\
& +\frac{1}{1-\alpha}\left\langle f(P(f))-P(f), J\left(x_{n+1}-P(f)\right)\right\rangle .
\end{aligned}
$$

It follows from condition (1), (48), and (55) that $\lambda_{n} \rightarrow 0$, $\sum_{n=1}^{\infty} \lambda_{n}=\infty$, and $\lim \sup _{n \rightarrow \infty} \sigma_{n} \leq 0$. Then, (57) reduces to

$$
\left\|x_{n+1}-P(f)\right\|^{2} \leq\left(1-\lambda_{n}\right)\left\|x_{n}-P(f)\right\|^{2}+\lambda_{n} \sigma_{n} .
$$

From Lemma 4 with $\mu_{n}=0$, we see that $\lim _{n \rightarrow \infty}\left\|x_{n}-P(f)\right\|=$ 0 . This completes the proof.

If $f=u \in K$ is a constant in Theorem 8 , then we have the following result.

Corollary 9. Let $E$ be a real strictly convex and uniformly smooth Banach space. Let $K$ be a nonempty, closed, and convex subset of $E$ and let $T_{i}$ be a nonexpansive mapping from $K$ into itself for $i \in N$. Assume that $F=\bigcap_{i=1}^{\infty} F\left(T_{i}\right) \neq \emptyset$ and $f \in \Pi_{K}$. Suppose that the sequences $\left\{\alpha_{n}\right\},\left\{\beta_{n}\right\},\left\{b_{n}\right\}$, and $\left\{\alpha_{n}+\beta_{n}\right\}$ in $(0,1)$ satisfy the following conditions:

(1) $\lim _{n \rightarrow \infty} \alpha_{n}=0, \sum_{n=1}^{\infty} \alpha_{n}=\infty$ and $0<$ $\liminf \inf _{n \rightarrow \infty} \beta_{n} \leq \lim \sup _{n \rightarrow \infty} \beta_{n}<1$;

(2) $\lim _{n \rightarrow \infty}\left|b_{n+1}-b_{n}\right|=0$ and $\liminf _{n \rightarrow \infty} b_{n}>0$.

Let $\left\{x_{n}\right\}$ be the sequence of successive approximations for the iterative method defined by

$$
\begin{aligned}
x_{0} & =x \in K, \\
y_{n} & =b_{n} x_{n}+\left(1-b_{n}\right) W_{n} x_{n}, \\
x_{n+1} & =\alpha_{n} u+\beta_{n} x_{n}+\left(1-\alpha_{n}-\beta_{n}\right) W_{n} y_{n}, \quad \forall n \geq 0,
\end{aligned}
$$

where $W_{n}$ is a mapping defined by (6). Then $\left\{x_{n}\right\}$ converges strongly to $x^{*} \in F$, where $x^{*}=P_{F}(u)$ and $P_{F}: K \rightarrow F$ is the unique sunny nonexpansive retraction; that is, $P$ satisfies the following property:

$$
\langle u-P u, J(p-P u)\rangle \leq 0, \quad \forall p \in F .
$$


Theorem 10. Let $E$ be a real strictly convex and uniformly smooth Banach space. Let $K$ be a nonempty, closed, and convex subset of $E$ and let $T_{i}$ be a nonexpansive mapping from $K$ into itself for $i \in \mathbb{N}$. Assume that $F=\bigcap_{i=1}^{\infty} F\left(T_{i}\right) \neq \emptyset$ and $f \in \Pi_{K}$. For given $x_{0} \in K$, let $\left\{x_{n}\right\}$ be the sequence of successive approximations for the iterative method defined by

$$
x_{n+1}=\alpha_{n} f\left(x_{n}\right)+\beta_{n} x_{n}+\left(1-\alpha_{n}-\beta_{n}\right) W_{n} x_{n}, \quad \forall n \geq 0,
$$

where $W_{n}$ is a mapping defined by (6), $\left\{\alpha_{n}\right\},\left\{\alpha_{n}+\beta_{n}\right\}$ are sequences in $(0,1)$, and $\left\{\beta_{n}\right\}$ is sequence in $[0,1)$ with $0<$ $\liminf _{n \rightarrow \infty} \beta_{n} \leq \lim \sup _{n \rightarrow \infty} \beta_{n}<1$. Then

(1) $\left\{x_{n}\right\}$ converges strongly to some common fixed point $p \in$ $F$ if and only if $\sum_{n=1}^{\infty} \alpha_{n}=\infty$ and $\lim _{n \rightarrow \infty} \alpha_{n}=0$;

(2) if $\left\{x_{n}\right\}$ converges strongly to some common fixed point $z \in F$, for given $f \in \Pi_{K}, P(f)=z=\lim _{n \rightarrow \infty} x_{n}$, then $P(f)$ is the unique solution of the following variational inequality in $F$ :

$$
\langle(I-f) P(f), J(P(f)-p)\rangle \leq 0, \quad \forall p \in F .
$$

Proof. (1) The sufficiency is obvious. Indeed, if we set $b_{n}=$ 1 for all $n \geq 0$ in (8), it follows from Theorem 8 that $\left\{x_{n}\right\}$ converges strongly to some common fixed point $p \in F$.

Now we prove necessity. Assume that $\left\{x_{n}\right\}$ converges strongly to some common fixed point $p \in F$. If we set $\beta_{n}=0$ in (62), we have

$$
x_{n+1}=\alpha_{n} f\left(x_{n}\right)+\left(1-\alpha_{n}\right) W_{n} x_{n} .
$$

Therefore, we obtain that

$$
\begin{aligned}
& \alpha_{n}\left\|f\left(x_{n}\right)-W_{n} x_{n}\right\|=\left\|x_{n+1}-W_{n} x_{n}\right\| \\
& \leq\left\|x_{n+1}-p\right\|+\left\|W_{n} x_{n}-p\right\| \\
& \leq\left\|x_{n+1}-p\right\|+\left\|x_{n}-p\right\| \longrightarrow 0, \\
& n \longrightarrow \infty .
\end{aligned}
$$

This implies that

$$
\limsup _{n \rightarrow \infty} \alpha_{n}\left\|f\left(x_{n}\right)-W_{n} x_{n}\right\|=\limsup _{n \rightarrow \infty} \alpha_{n}\|f(p)-p\|=0 .
$$

Notice that in general $f(p)$ is not equal to $p$. However, since $f$ is an arbitrary contraction, we get $\lim \sup _{n \rightarrow \infty} \alpha_{n}=0$. Thus, $\lim _{n \rightarrow \infty} \alpha_{n}=0$.

On the other hand, let us set $f=0, \beta_{n}=0, K=\{x \in E$ : $\|x\| \leq 1\}$, and $T_{i}=I: K \rightarrow K$ in (62) for all $i \in N$, where $I$ is the identity operator. Clearly, 0 is the unique common fixed point of $\left\{T_{i}\right\}_{i=1}^{\infty}$ and $W_{n}=I$ for all $n \in N$. Moreover, we have

$$
\begin{aligned}
x_{n+1} & =\left(1-\alpha_{n}\right) x_{n}=\left(1-\alpha_{n}\right)\left(1-\alpha_{n-1}\right) x_{n-1} \\
& =\cdots=\prod_{i=1}^{n}\left(1-\alpha_{i}\right) x_{0} .
\end{aligned}
$$

Because $x_{n} \rightarrow 0 \in F$, we obtain

$$
0=\lim _{n \rightarrow \infty}\left\|x_{n+1}-0\right\|=\lim _{n \rightarrow \infty} \prod_{i=1}^{n}\left(1-\alpha_{i}\right)\left\|x_{0}\right\| .
$$

Therefore, we get that $\prod_{i=1}^{\infty}\left(1-\alpha_{i}\right)=0$; equivalently, $\sum_{n=1}^{\infty} \alpha_{n}=$ $\infty$.

(2) If $\lim _{n \rightarrow \infty} x_{n}=z=P(f)$, for all $f \in \Pi_{K}$, we define a contraction $W_{t}: K \rightarrow K$ by

$$
W_{t} x=t f(x)+(1-t) W x, \quad \forall x \in K
$$

Banach's contraction principle guarantees that $W_{t}$ has a unique fixed point $x_{t}$ in $K$. It follows from Lemmas 2 and 6 that

$$
\lim _{n \rightarrow \infty} x_{n}=\lim _{t \rightarrow 0} x_{t}=P(f)=z \in F, \quad \forall f \in \Pi_{K},
$$

and $P(f)$ is the unique solution of the following variational inequality in $F$ :

$$
\langle(I-f) P(f), J(P(f)-p)\rangle \leq 0, \quad \forall p \in F .
$$

If we set $\beta_{n}=0$ in (62), we have the following result.

Corollary 11. Let $E$ be a real strictly convex and uniformly smooth Banach space. Let $K$ be a nonempty, closed, and convex subset of $E$ and let $T_{i}$ be a nonexpansive mapping from $K$ into itself for $i \in \mathbb{N}$. Assume that $F=\bigcap_{i=1}^{\infty} F\left(T_{i}\right) \neq \emptyset$ and $f \in \Pi_{K}$. For given $x_{0} \in K$, let $\left\{x_{n}\right\}$ be the sequence of successive approximations for the iterative method defined by

$$
x_{n+1}=\alpha_{n} f\left(x_{n}\right)+\left(1-\alpha_{n}\right) W_{n} x_{n}, \quad \forall n \geq 0,
$$

where $W_{n}$ is a mapping defined by (6) and $\left\{\alpha_{n}\right\}$ is sequence in $(0,1)$. Then

(1) $\left\{x_{n}\right\}$ converges strongly to some common fixed point $p \in$ $F$ if and only if $\sum_{n=1}^{\infty} \alpha_{n}=\infty$ and $\lim _{n \rightarrow \infty} \alpha_{n}=0$;

(2) if $\left\{x_{n}\right\}$ converges strongly to some common fixed point $z \in F$, for given $f \in \Pi_{K}, P(f)=z=\lim _{n \rightarrow \infty} x_{n}$, then $P(f)$ is the unique solution of the following variational inequality in $F$ :

$$
\langle(I-f) P(f), J(P(f)-p)\rangle \leq 0, \quad \forall p \in F .
$$

Remark 12. Corollary 11 improves Theorem 4.2 of [10] from a single nonexpansive mapping to an infinite countable family of nonexpansive mappings and generalizes the corresponding results by $\mathrm{Xu}$ [19], Halpern [21], Lions [22], and Wittmann [23] to the viscosity methods. And our iterative method presented in this paper can be reviewed as a refinement and modification of the iterative methods in the literature. Moreover we show necessary and sufficient conditions for the convergence of the viscosity iterative algorithm for finding approximate common fixed points of an infinite family of nonexpansive mappings. 


\section{Conflict of Interests}

The authors declare that there is no conflict of interests regarding the publication of this paper.

\section{Acknowledgments}

This work was supported in part by the National Natural Science Foundation of China (Grant no. 61374081) and the Natural Science Foundation of Guangdong Province (S2013010013034).

\section{References}

[1] P. Hartman and G. Stampacchia, "On some nonlinear elliptic differential functional equations," Acta Mathematica, vol. 115, pp. 153-188, 1996.

[2] P. T. Harker and J.-S. Pang, "Finite-dimensional variational inequality and nonlinear complementarity problems: a survey of theory, algorithms and applications," Mathematical Programming, vol. 48, no. 2, pp. 161-220, 1990.

[3] A. Cochocki and R. Unbehauen, Neural Networks for Optimization and Signal Processing, Wiley, New York, NY, USA, 1993.

[4] F. Facchinei and J. Pang, Finite-Dimensional Variational Inequalities and Nonlinear Complementarity Problems, Springer, New York, NY, USA, 2003.

[5] X. Qin, S. Y. Cho, and S. M. Kang, "Iterative algorithms for variational inequality and equilibrium problems with applications," Journal of Global Optimization, vol. 48, no. 3, pp. 423-445, 2010.

[6] F. Deutsch and I. Yamada, "Minimizing certain convex functions over the intersection of the fixed point sets of nonexpansive mappings," Numerical Functional Analysis and Optimization, vol. 19, no. 1-2, pp. 33-56, 1998.

[7] G. Marino and H.-K. Xu, "A general iterative method for nonexpansive mappings in Hilbert spaces," Journal of Mathematical Analysis and Applications, vol. 318, no. 1, pp. 43-52, 2006.

[8] H. K. Xu, "An iterative approach to quadratic optimization," Journal of Optimization Theory and Applications, vol. 116, no. 3, pp. 659-678, 2003.

[9] A. Moudafi, "Viscosity approximation methods for fixed-points problems," Journal of Mathematical Analysis and Applications, vol. 241, no. 1, pp. 46-55, 2000.

[10] H.-K. Xu, "Viscosity approximation methods for nonexpansive mappings," Journal of Mathematical Analysis and Applications, vol. 298, no. 1, pp. 279-291, 2004.

[11] Y. Yao, R. Chen, and J.-C. Yao, "Strong convergence and certain control conditions for modified Mann iteration," Nonlinear Analysis: Theory, Methods \& Applications, vol. 68, no. 6, pp. 1687-1693, 2008.

[12] K. Shimoji and W. Takahashi, "Strong convergence to common fixed points of infinite nonexpansive mappings and applications," Taiwanese Journal of Mathematics, vol. 5, no. 2, pp. 387404, 2001.

[13] H. H. Bauschke and J. M. Borwein, "On projection algorithms for solving convex feasibility problems," SIAM Review, vol. 38, no. 3, pp. 367-426, 1996.

[14] D. C. Youla, "Mathematical theory of image restoration by the method of convex projections," in Image Recovery: Theory and Applications, H. Stark, Ed., pp. 29-77, Academic Press, Orlando, Fla, USA, 1987.
[15] A. N. Iusem and A. R. de Pierro, "On the convergence of Han's method for convex programming with quadratic objective," Mathematical Programming B, vol. 52, no. 1-3, pp. 265-284, 1991.

[16] Y. J. Cho, S. M. Kang, and X. Qin, "Approximation of common fixed points of an infinite family of nonexpansive mappings in Banach spaces," Computers \& Mathematics with Applications, vol. 56, no. 8, pp. 2058-2064, 2008.

[17] K. Deimling, Nonlinear Functional Analysis, Springer, New York, NY, USA, 1985.

[18] R. E. Bruck, Jr., "Nonexpansive projections on subsets of Banach spaces," Pacific Journal of Mathematics, vol. 47, pp. 341-355, 1973.

[19] H.-K. Xu, "Iterative algorithms for nonlinear operators," Journal of the London Mathematical Society, vol. 66, no. 1, pp. 240-256, 2002.

[20] T. Suzuki, “Strong convergence of Krasnoselskii and Mann's type sequences for one-parameter nonexpansive semigroups without Bochner integrals," Journal of Mathematical Analysis and Applications, vol. 305, no. 1, pp. 227-239, 2005.

[21] B. Halpern, "Fixed points of nonexpanding maps," Bulletin of the American Mathematical Society, vol. 73, pp. 957-961, 1967.

[22] P.-L. Lions, "Approximation de points fixes de contractions," Comptes Rendus de l'Académie des Sciences, vol. 284, no. 21, pp. A1357-A1359, 1977.

[23] R. Wittmann, "Approximation of fixed points of nonexpansive mappings," Archiv der Mathematik, vol. 58, no. 5, pp. 486-491, 1992. 


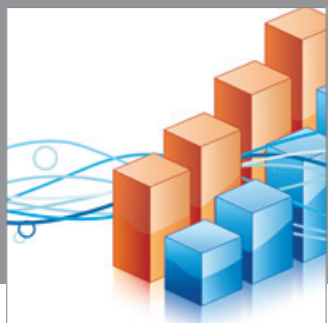

Advances in

Operations Research

mansans

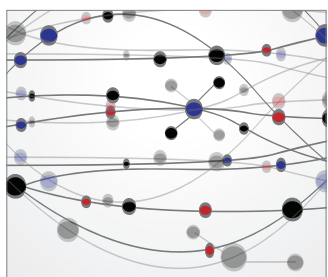

The Scientific World Journal
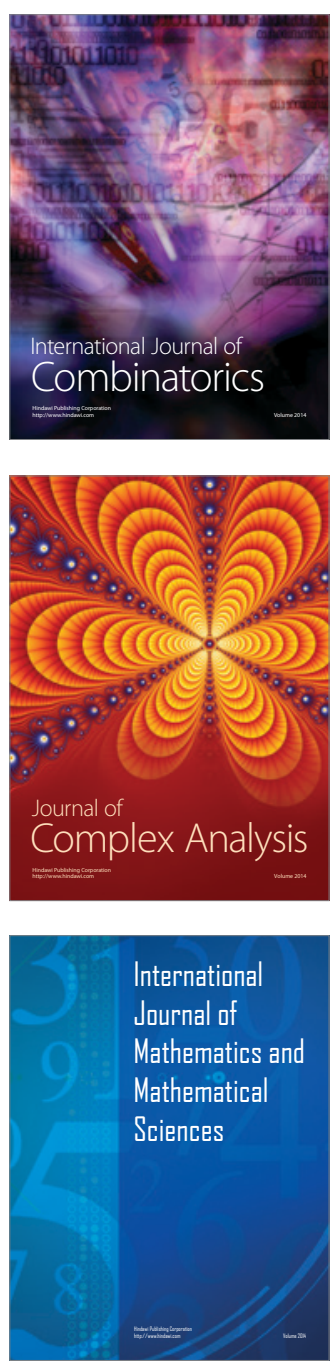
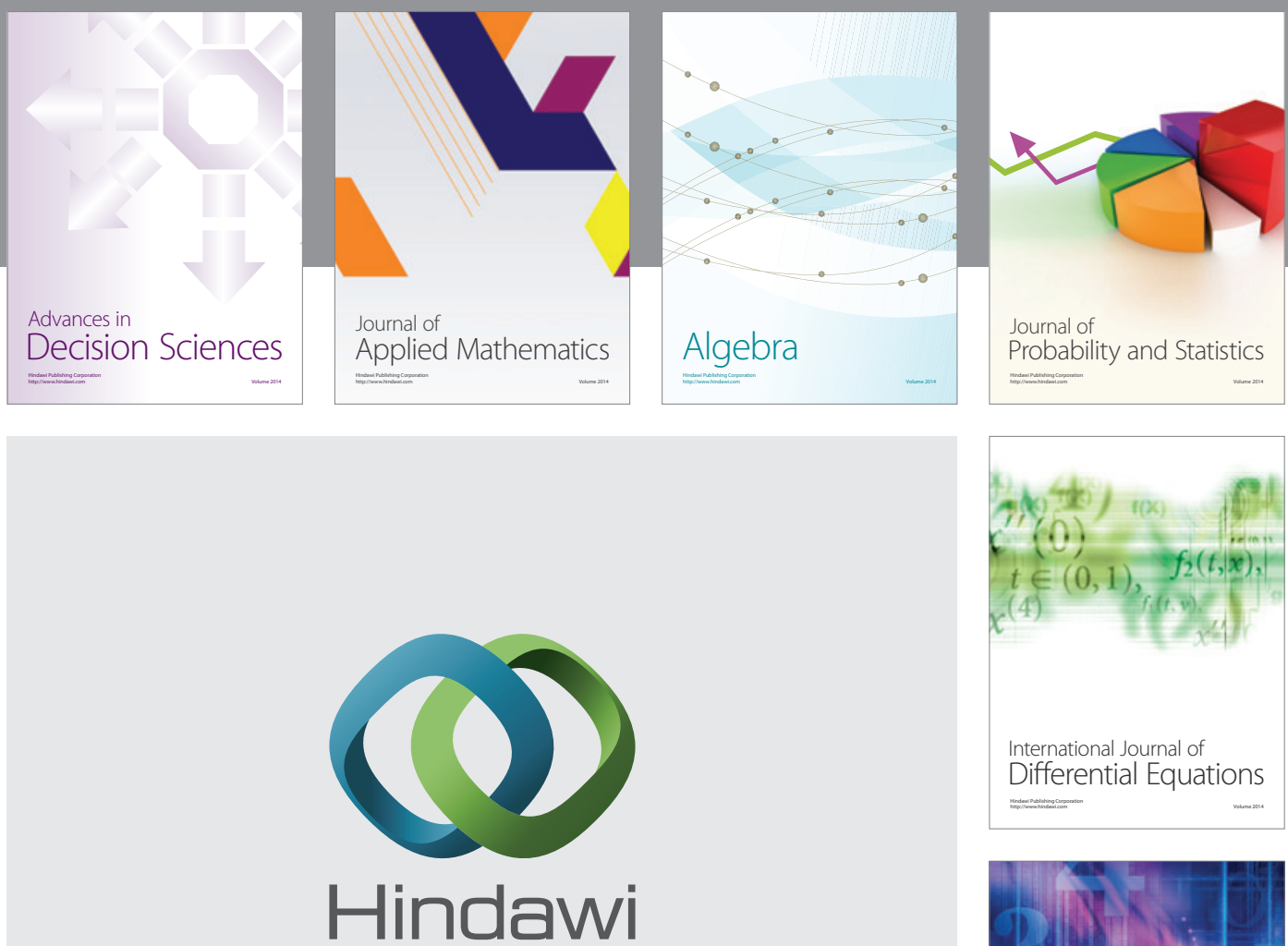

Submit your manuscripts at http://www.hindawi.com
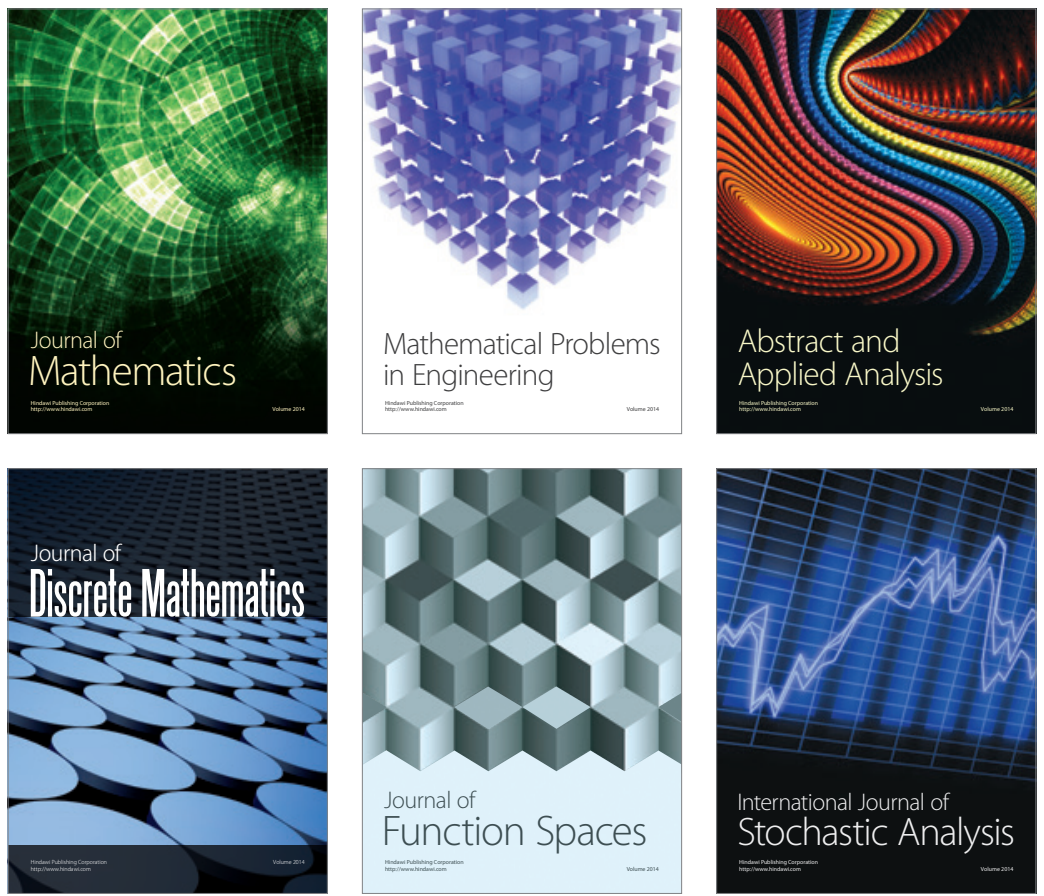

Journal of

Function Spaces

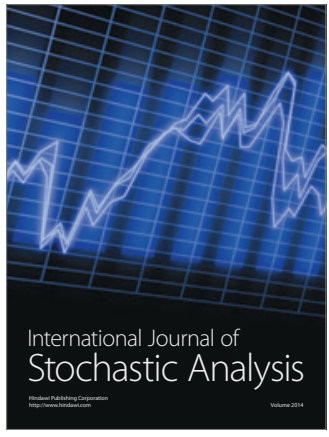

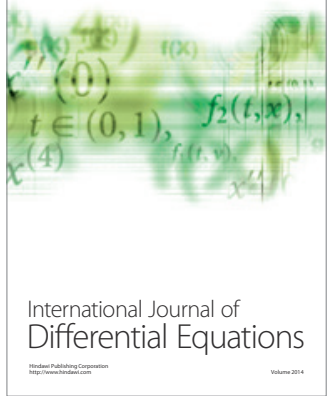
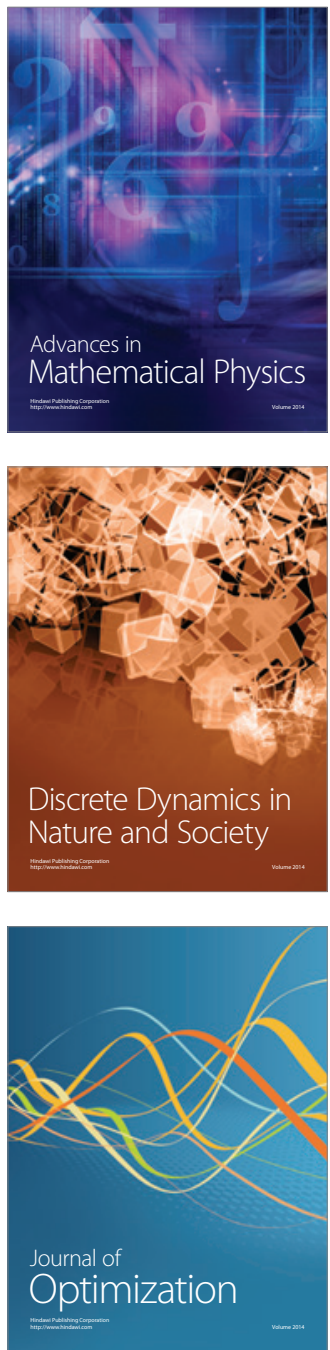